\title{
Protein kinase R-like ER kinase and its role in endoplasmic reticulum stress-decided cell fate
}

\author{
Z Liu ${ }^{1,2}$, Y Lv ${ }^{1,2}$, N Zhao ${ }^{1}$, G Guan ${ }^{*, 1}$ and J Wang ${ }^{*, 1}$
}

Over the past few decades, understandings and evidences concerning the role of endoplasmic reticulum (ER) stress in deciding the cell fate have been constantly growing. Generally, during ER stress, the signal transductions are mainly conducted by three ER stress transducers: protein kinase R-like endoplasmic reticulum kinase (PERK), inositol-requiring kinase 1 (IRE1) and activating transcription factor 6 (ATF6). Consequently, the harmful stimuli from the ER stress transducers induce apoptosis and autophagy, which share several crosstalks and eventually decide the cell fate. The dominance of apoptosis or autophagy induced by ER stress depends on the type and degree of the stimuli. When ER stress is too severe and prolonged, apoptosis is induced to eliminate the damaged cells; however, when stimuli are mild, cell survival is promoted to maintain normal physiological functions by inducing autophagy. Although all the three pathways participate in ER stress-induced apoptosis and autophagy, PERK shows several unique characteristics by interacting with some specific downstream effectors. Notably, there are some preliminary findings on PERK-dependent mechanisms switching autophagy and apoptosis. In this review, we particularly focused on the novel, intriguing and complicated role of PERK in ER stress-decided cell fate, and also discussed more roles of PERK in restoring cellular homeostasis. However, more in-depth knowledge of PERK in the future would facilitate our understanding about many human diseases and benefit in searching for new molecular therapeutic targets.

Cell Death and Disease (2015) 6, e1822; doi:10.1038/cddis.2015.183; published online 30 July 2015

Facts

- Protein kinase R-like endoplasmic reticulum kinase (PERK) is one of the major transducers of endoplasmic reticulum (ER) stress, participating in regulating fundamental cell functions.

- Composed of the cytosolic and kinase domains, ERK is activated in a lined-up formation after interaction with the peptide chain of an unfolded/misfolded protein.

- Signals of apoptosis and autophagy induced by ER stress could be transducted through PERK pathway to trigger cell death or to maintain cell survival.

- There is a switching mechanism between autophagy and apoptosis, which is regulated by PERK.

\section{Open Questions}

- How to explain the finding that PERK deficiency presented stronger protective effect against apoptosis rather than activating transcription factor 6 (ATF6) or inositol-requiring kinase 1 (IRE1) deletion?
- Are there any other downstream pathways of PERK when inducing cell apoptosis and autophagy?

- What are the exact interaction mechanisms and significance of crosstalk network among PERK-governed pathways in ER stress?

ER was spotted by KR Porter, A Claude and EF Fullam in 1945 in cultured mice fibroblasts. ${ }^{1}$ ER was found in almost all kinds of mammalian eukaryotic cells (except mature red blood cells). ER has been considered as a tubular system composed of a biomembrane, providing pathways for intracellular material transportation and a platform for various biological enzymatic reactions. ${ }^{2}$ ER is considered as one of the major vital organelles because it executes and participates in various fundamental biological functions including protein synthesis, steroid hormone synthesis, posttranslational protein modification, peptide chain folding, glucose concentration regulation, calcium homeostasis and lipid metabolism. ${ }^{3-5}$

ER is critically involved in protein processing, which was described as a 'protein folding factory'. By coordinating activities of protein folding/modifying enzymes and interactions

\footnotetext{
${ }^{1}$ Department of Cardiology, Shaanxi Provincial People's Hospital, Xi'an, China

${ }^{*}$ Corresponding author: Professor G Guan or Professor J Wang, Department of Cardiology, Shaanxi Provincial People's Hospital, No. 256, Friendship West Road, Xi'an 710000, China. Tel: +86 29 85251331; Fax: +86 29 85236987; E-mail: guangongch@yahoo.com.cn or Junkuiwang @yeah.net

${ }^{2}$ These authors contributed equally to this work.

Abbreviations: ER endoplasmic reticulum; ERAD ER-associated degradation; ERQC ER quality control; UPR, unfolded protein response; GRP, glucose-regulated protein; Hsp heat shock protein; ATF, activating transcription factor; PERK protein kinase R-like endoplasmic reticulum kinase; IRE, inositol requiring kinase; RIDD regulated IRE1-dependent decay of $\mathrm{mRNA}$; CHOP C/BEP homologous protein; XBP, X-box binding protein; elF eukaryotic initiation factor; DR death receptor; ERO, ER oxidase; ORF, open reading frames; CREB cAMP-responsive element-binding protein; CIAP, cellular inhibitor of apoptosis; TDAG T-cell death-associated gene; NRF, nuclear respiratory factor; TRIB Tribbles homolog; CaN, calcineurin; FKBP FK506-binding protein; RyR, ryanodine receptor; DAPK death-associated protein kinase; mTOR mammalian target of rapamycin; AMPK, AMP-activated protein kinase

Received 03.2.15; revised 23.5.15; accepted 26.5.15; Edited by GM Fimia
} 
of molecular chaperones, ER optimizes the microenvironment for posttranslational processing of nascent proteins. ${ }^{6}$ Correctly folded and modified proteins were then transported to the Golgi complex, which is responsible for protein maturation and distribution. The unfolded and misfolded proteins were deleted by ER-associated degradation (ERAD) system and cytosolic proteasomes. ${ }^{7}$ However, certain pathological conditions, such as extracellular blood glucose concentration fluctuation, oxidative stress, toxic agents/drug and radioactive radiation, would lead to overproduction of unfolded/misfolded proteins. The accumulation of these unfolded/misfolded proteins in ER lumen aggravates the burden of ER quality control system and eventually initiates unfolded protein response (UPR). ${ }^{8}$

The UPR was first described by Kozutsumi et al. ${ }^{9}$ in the $1980 \mathrm{~s}$ in mammalian cells in response to stressful conditions. ${ }^{9}$ UPR was considered a protective response to suspend protein translation massively but to induce some specific gene translations, which intend to restore the ER protein folding capacity. The transcription and translation of several ER-resident proteins, such as glucose-regulated protein 78 (GRP78), which belongs to heat-shock protein 70 (Hsp70) family, was markedly upregulated. ${ }^{10}$ Similar phenomenon was also observed in yeast where the expression of Kar2p, a GRP78 homolog, was increased too. ${ }^{11}$ However, when the external stressful factors fail to withdraw, the accumulation rate of misfolded proteins in the ER lumen would overwhelm the handling capacity of the ERAD system, initiating a pathological cellular stressful condition called ER stress.

\section{Downstream Signaling Pathways of UPR Sensors}

Main signaling arms of ER stress. Generally, the harmful signaling was considered mainly sensed by three ERresident transmembrane molecules, which were referred to as ATF6, IRE1 and PERK. ${ }^{12}$ As one of the most highly expressed ER chaperones, GRP78 was known to bind to the hydrophobic domains of proteins with its C-terminal substrate-binding domain to protect protein against misfolding. This process was thought energy consuming because GRP78 is actually an ATPase for its N-terminal ATPase domain. ${ }^{13}$ In resting cells under physiological conditions, the activities in ATF6-, IRE1- and PERK-governed signaltransduction branches were blocked when GRP78 binds to their lumenal domains. ${ }^{14}$ However, when affected by sustained harmful stress, GRP78 would disassociate from these sensors to initiate ER stress. ATF6 is activated after being cleaved, whereas PERK and IRE1 are activated by selftransphosphorylation. It was reported that the sensitivities to external stressors vary among these signaling branches. The activation of PERK-governed signaling was almost simultaneous with the onset of ER stress (GRP78 disassociation), followed by activation of ATF6 and then IRE1 signaling pathways. $^{12,15}$

\section{PERK is one of the major signaling pathways of ER stress}

ATF6: ATF6 is a type-Il transmembrane protein located on the ER. The stress signal could be sensed by lumenal
C-terminal region of ATF6 right after exposure to stressful conditions rapidly. After the disassociation from GRP78, ATF6 translocates to the Golgi complex where the full-length ATF6 is cleaved by site-1 and site-2 proteases. $^{16}$ The generated $50 \mathrm{kDa}$ fragment is bioactive because it contains the bZIP nuclear transcription activation domain that originated from the N-terminal region of ATF6. This fragment, also referred to as ATF6 P50, then translocates to the nucleus to regulate survival-related gene expression such as C/BEP homologous protein (CHOP) and X-box-binding protein 1 (XBP1). ${ }^{17}$

IRE1: The endoribonuclease domain and the Ser/Thr kinase domain endow IRE1 dual enzymatic activities. The activation of IRE1 signaling was found delayed as the transcription of its substrate XBP1 mRNA is upregulated after activation of the ATF6 signaling pathway. ${ }^{18}$ After activation by self-phosphorylation, right after dissociation from GRP78, the phosphorylated IRE1 introduces an unconventional splicing by removing an intron to generate a spliced variant of XBP1, which is called SXBP1. ${ }^{19}$ It has been proved that SXBP1 had a part in regulating transcriptions of ER stress proteins, which were found involved in assisting protein folding, maturation and transportation, as well as degrading misfolded proteins. ${ }^{20}$ Furthermore, IRE1 was also considered a key initiator of ER stress-induced cell death. ${ }^{21}$ According to several recent studies, cell death was promoted by regulated IRE1dependent decay of mRNA, which is a process targeting and degrading protein folding-related mRNAs. ${ }^{22}$

PERK: The a-subunit of eukaryotic initiation factor 2 (elF2a) phosphorylation is executed by elF2 $a$ kinase family, which is considered protective in cells engaging various stimuli by biasing general protein synthesis but initiating stress-related protein production. As most transcription processes are shut down, ER lumen protein accumulation is, therefore, attenuated and the ER stress is relived. It is widely accepted that there are mainly four members of elF2a kinase family, namely PERK, protein kinase double-stranded RNAdependent, heme-regulated inhibitor and general control non-derepressible-2. A wide range of cellular stress, such as heme deprivation, UV irradiation, amino-acid starvation and viral infection, would activate these kinases, which subsequently trigger the phosphorylation of elF2a. ${ }^{23}$ In ER stress, right after disassociation of GRP78, the activation of PERK signaling pathway is initiated upon its dimerization and autophosphorylation. ${ }^{24}$ Then, elF2a, which is one of the PERK's downstream effectors, is phosphorylated to suppress the general gene translations by inhibiting ribosome transportation of initiator methionyl-tRNAi ${ }^{\mathrm{Met}}{ }^{25}$ Notably, translations of genes containing internal ribosomal entry sites were selectively enhanced after phosphorylation of elF $2 a{ }^{26}$ The canonical example is the ATF4 (activating transcription factor 4) gene encoded mRNA. The translation of ATF4 after scanning ribosome association is a process depending on elF2-GTP/Met-tRNA ${ }_{i}{ }^{\text {Met }}$ levels, which is reduced during ER stress. $^{27,28}$ 


\section{The Molecular Structure and Activation of PERK}

PERK is a protein kinase that belongs to elF2a kinase subfamily. PERK is composed of the cytoplasmic and kinase domains. The cytoplasmic domain senses the accumulation of unfolded/misfolded proteins in the ER lumen. After stimulation, PERK is activated by autophosphorylation of its kinase domain and acquired full catalytic activity to further phosphorylate elFa at Ser51 specifically. ${ }^{29}$ Similar to most typical protein kinases, the structure of the kinase domain contains a C-terminal lobe (C-lobe) and an N-terminal lobe (N-lobe). There is a short hinge loop linking the two lobes. The $\mathrm{N}$-lobe comprises three $a$-helices and five $\beta$-strands, whereas the C-lobe comprises two short $\beta$-strands, seven $\alpha$-helices and a long activation loop ${ }^{30}$ (Figure 1a).

Located on the ER membrane, PERK is presented as a homodimer. The cytoplasmic domain is binded by the ER chaperone GRP78 under ER stress-free conditions. ER stress initiation would facilitate the disassociation of GRP78 from the cytoplasmic domain. Then, the unfolded/misfolded proteins in the ER lumen bind to MHC-like grooves of the cytoplasmic domain and subsequently trigger stack of PERK homodimers. Along the polypeptide of unfolded/misfolded proteins, the PERK dimers are lined up. ${ }^{30}$ This steric configuration allows the activation loop of one dimer reach the catalytic site of the other dimer to cause selfphosphorylation. Then, the downstream molecules of PERK are recruited and phosphorylated (Figure 1b).

\section{Role of PERK in ER Stress-Mediated Cell Apoptosis}

In response to excessive ER stress, proapoptotic events are intended to be induced. Although there are still debates and arguments around molecular events in stress-induced apoptosis, a number of cell death-related signaling pathways are involved in Figure 2.

Shared pathways. After exposure to sustained and excessive ER stress, the above-mentioned three branches, IRE1, PERK and ATF6 signaling, would lead to programmed cell death through several common pathways. CHOP and caspase-mediated apoptotic pathways are the most studied ones. These two pathways are not exclusive and even closely connected. In most cases, CHOP-induced apoptosis is the form of caspase-dependent cell death. However, there are still other unique molecules that receive the apoptotic signaling transduced by CHOP.

CHOP: As a major component of ER stress-induced apoptosis, CHOP-mediated pathway is the most described and characterized pathway in ER stress-induced cell death. CHOP is also known as GADD153 (growth arrest and DNA damage 153), whose activation is induced by ATF6 and PERK. ${ }^{17,31}$ It is now generally accepted that CHOP is a major molecule regulating ER stress-induced apoptosis. Apoptotic molecules such as death receptor 5, GADD34 and ER oxidase 1 and so on are considered the target of $\mathrm{CHOP}^{32,33}$ As CHOP-related apoptotic signaling network is complicated, more investigations are still needed to interpret the exact mechanism.

Caspase cascade: Caspase cascade activation is a wellknown proapoptotic event that is also involved in ER stress-induced apoptosis. ${ }^{34}$ Several members, including caspase-2, caspase-4 (human), caspase-12 (rodents), a

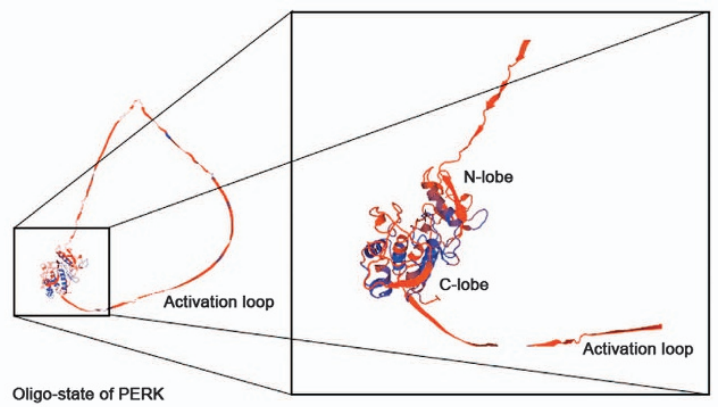

(I)

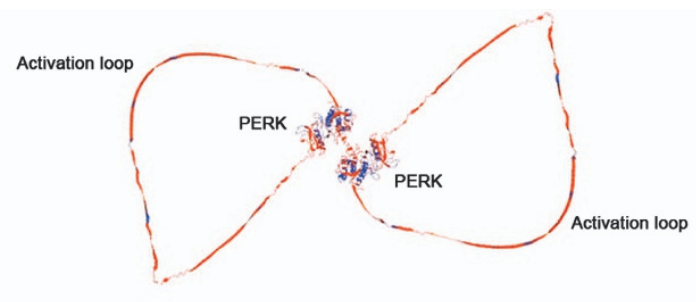

Homodimer-state of PERK

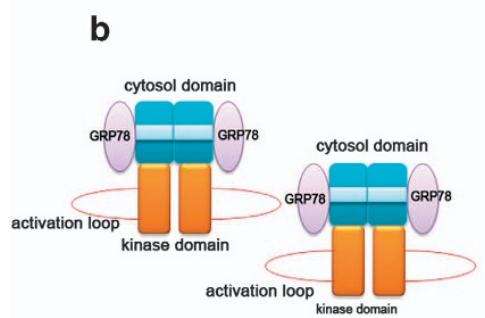

(I)

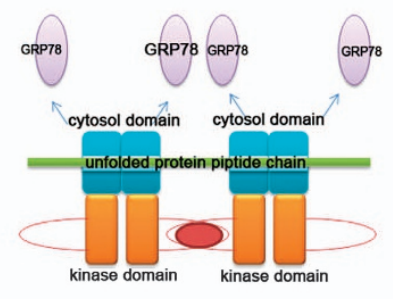

(II)

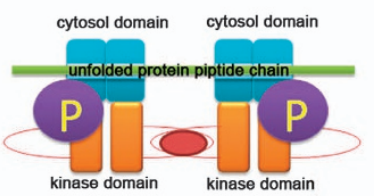

(III)

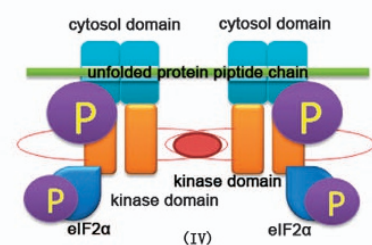

(IV)

Figure 1 Molecular structure of PERK kinase domain and 'line-up' activation mechanism. (a) The presumed three-dimensional (3D) molecular model of PERK kinase domain. (I) The oligostate of PERK kinase domain. This domain could be divided into N-lobe and C-lobe, which are connected by a short hinge loop. There is a distinctive long activation loop in this structure. (II) Two individual PERK molecules dimerize to establish the homodimer state of PERK kinase domain, which is the most common form of PERK. (b) (I) At resting state without ER stress, GRP78 binds to the cytosol domain of dimerized PERK. (II) Under external harmful stimuli, the unfolded protein accumulate in the ER lumen to initiate ER stress by disassociating GRP78 from PERK. Then, the peptide chain of an unfolded protein bind to MHC-like grooves of the cytoplasmic domain to 'line up' the stacked PERK dimers. (III) The activation loop of neighboring PERK kinase domain interact with each other to trigger autophosphorylation of PERK. (IV) elF2 $\alpha$ are recruited and phosphorylated by activated PERK 


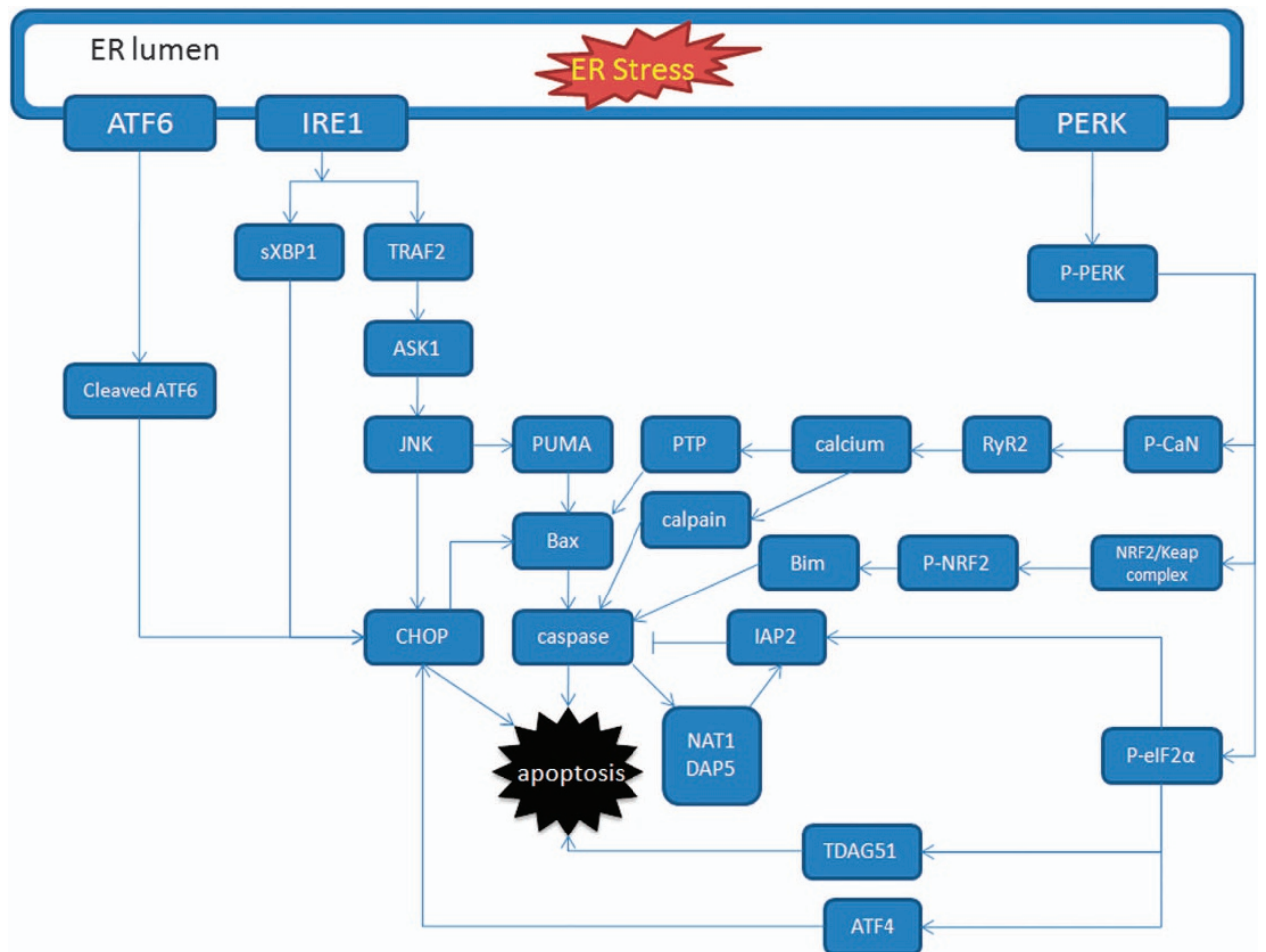

Figure 2 Schematic diagram of signal-transduction network during ER stress-induced cell apoptosis. Apoptotic signals are transduced through ATF6-, IRE1- and PERKgoverned signaling pathways in ER stress-induced apoptosis. This diagram mainly showed PERK-associated pathways, whereas ATF6- and IRE1-regulated pathways are briefly demonstrated. According to previous studies, in ER stress-induced apoptosis, PERK/elF2 $\alpha /$ ATF4, PERK/CaN, PERK/elF2 $\alpha / T D A G 51$, PERK/elF2 $\alpha /$ IAP2 and PERK/NRF2 pathways are considered PERK-associated

Table 1 Several molecules related with PERK-induced cell apoptosis

\begin{tabular}{|c|c|c|c|c|c|c|}
\hline Molecules & $\begin{array}{l}\text { Upstream } \\
\text { molecules }\end{array}$ & $\begin{array}{l}\text { Effect of upstream } \\
\text { molecules }\end{array}$ & $\begin{array}{l}\text { Direct/indirect } \\
\text { interact with PERK }\end{array}$ & $\begin{array}{l}\text { Downstream } \\
\text { molecules }\end{array}$ & $\begin{array}{l}\text { Effect to downstream } \\
\text { molecules }\end{array}$ & $\begin{array}{l}\text { Consequence of } \\
\text { activation }\end{array}$ \\
\hline elF2a & PERK & Activation & Direct & ATF4 & Activation & Proapoptosis \\
\hline ATF4 & PERK, elF2 $a$ & Activation & Indirect & CHOP, Noxa & Activation & Proapoptosis \\
\hline clAPs & $\begin{array}{l}\text { PERK, elF2 } a \text {, } \\
\text { NAT1, DAP5 }\end{array}$ & Activation & Unknown & $\begin{array}{l}\text { Caspase- } 3 \text {, caspase- } 7 \text {, } \\
\text { caspase- } 9\end{array}$ & Inhibition & Antiapoptosis \\
\hline TDAG51 & PERK, elF2 $a$ & Activation & Unknown & CD95/Fas & Activation & Proapoptosis \\
\hline NRF & PERK & Activation & Direct & $\mathrm{Bcl} 2$ & Activation & Antiapoptosis \\
\hline TRIB3 & $\begin{array}{l}\text { PERK, ATF4, } \\
\text { CHOP }\end{array}$ & Activation & Indirect & $\mathrm{NF}-\kappa \mathrm{B}$, Notch 1 & Activation & Proapoptosis \\
\hline CaN & PERK & Activation & Direct & RyR2 & Activation & Proapoptosis \\
\hline
\end{tabular}

caspase-3, caspase-7 and caspase- 9 , were believed to have roles in this process. It was suggested that caspase-12 (caspase-4) was specific to death signals in ER stress rather than other cell death mechanisms. ${ }^{35,36}$ Caspase-12 (caspase-4) is dispensable for cell death but crucial for ER-stressinduced apoptosis. Caspase-2 (caspase-4) was found located on the ER membrane, the activation of which would lead to caspase-9/caspase-3 activation, resulting in programmed cell death.

PERK-associated pathways. The three branches of ER stress, PERK, IRE1 and ATF6, show their uniqueness when transducing survival signals in ER stress. As a central regulator of ER stress, PERK decides cell fate by interacting with its own downstream molecules to form corresponding pathways (Table 1).

elF2a/ATF4: Upon activation of PERK in ER stress, 805 ribosome assembly and massive protein synthesis are inhibited. This inhibition effect was believed to be due to phosphorylation of elF2a by activated PERK, ${ }^{26,37}$ which would conduct proapoptotic signaling. On the other hand, the dephosphorylation of elF2a could suppress PERK signaling by conducting prosurvival signaling. For example, a recent research showed that after elF2a was dephosphorylated by GADD34, the downstream ATF4/CHOP signaling was suppressed. ${ }^{38}$ Therefore, elF2a could be treated as one of the critical junctures in PERK-mediated signaling. 
Unlike most genes, ATF4 is characterized by its upstream open reading frames (ORFs) located on the 5'-untranslated region. Thus, these ORFs enable ATF4 escape from massive gene translation suspension, whereas the translation of ATF4 is often ceased under normal conditions without ER stress. $^{39,40}$ As a member of cAMP-responsive elementbinding protein family, ATF4 has a broad spectrum of targeted molecules. It was documented that ATF4 acted as a prodeath factor under ER stress. ${ }^{41}$ The cell death-inducing function of ATF4 is attributed to the initiation transcriptions of apoptotic factors including $\mathrm{CHOP}$ and Noxa. ${ }^{42} \mathrm{Noxa}$ is one of $\mathrm{BH}$-only proteins, which are found as inhibitors of prosurvival proteins such as Bcl-2 and activators of proapoptotic proteins such as Bak and Bax. ${ }^{43}$

Cellular inhibitor of apoptosis: IAP is a gene family that encodes IAP proteins, which were initially found in host cells undergoing baculoviral infection. IAPs were described critical in mediating host cell viability. ${ }^{44}$ The most frequently described membranes of cellular inhibitor of apoptosis (cIAP) proteins are clAP1, clAP2 and X-chromosome-linked IAP (XIAP). ${ }^{45}$ Previously, it has been shown that in response to stimuli from ER stress, expression of cIAP1, clAP2 and XIAP was elevated, which was protective against cell death. ${ }^{46} \mathrm{clAP}$ machinery in ER stress was reported in a PERK-dependent manner. ${ }^{46}$ The increased clAP expression was found to delay the onset of ER stress-induced apoptosis. Caspase cascade is activated upon ER stress and further cleaves molecules such as $N$-acetyltransferase 1 (NAT1) and death-associated protein 5 (DAP5). ${ }^{47,48}$ The resulting cleavage products would in turn activate internal ribosome entry site of IAP2, elevating the translation of IAP2. It was demonstrated that IAP silencing increased the sensitivity to ER stress-induced apoptosis.

T-cell death-associated gene 51: T-cell death-associated gene 51 (TDAG51) is a member of pleckstrin homologyrelated domain family, which was found as a proapoptotic factor promoting cell apoptosis. ${ }^{49}$ The central motif of TDAG51 consists of pleckstrin homology domain and several C-terminal proline-glutamine/histidine repeats. This characterized structure endows TDAG51 the activity of transcriptional regulation, participating in inducing apoptosis. The activation of PERK/elF2 $a$ would lead to the inhibition of most mRNA translation but inducing several gene expressions, including GRP78, CHOP and TDAG51. ${ }^{50}$ Although not fully clarified, previous studies showed that the activation of TDAG51 is an ER stress-induced elF2a-dependent process. $^{51}$ Thus, it is reasonable to speculate that TDAG51 is one of the downstream effector of PERK regulating cell fate.

Nuclear respiratory factor: Nuclear respiratory factors (NRFs) are members of the CNC-basic leucine zipper (CNC-bZIP) family of transcriptional factors. The structures of NRFs are highly conserved. In resting cells, by associating with cytoskeletal anchor protein Kelch-like Ech-associated protein 1 (Keap1), NRF2 is resident in latent cytoplasmic complexes. ${ }^{52}$ Results from previous work demonstrated that NRF2 was one of the direct substrate molecules of
PERK. ${ }^{53,54}$ PERK-dependent phosphorylation is sufficient and necessary to initiate the separation of NRF2 from Keap1 with the assistance of NRF1. ${ }^{55}$ NRF2 - / - cells were found more sensitive to ER stress- induced apoptosis, ${ }^{56,57}$ indicating that NRF2 is a antisurvival factor.

Tribbles homolog 3: Tribbles homolog 3 (TRIB3) refers to the mammalian homolog of Drosophila tribbles and draw attention because of its correlation with cell death. TRIB3 was initially located in neuronal cells undergoing apoptosis as a cell death-inducible protein kinase. ${ }^{58}$ In ER-stressed cells, TRIB3 expression was elevated. Further investigation showed that TRIB3 interacted directly with $\mathrm{CHOP}$ without influencing the expression level of $\mathrm{CHOP}$, whereas $\mathrm{CHOP}$ overexpression activated the promoter activity of TRIB3. ${ }^{59}$ The promoter region pTRIB3-Luc1, 2, 5 and 6 was identified as the ER stress response element with a CHOP binding site inside. According to previous studies, the expression of TRIB3 was induced by the PERK/ATF4 pathway. ${ }^{60}$ Notably, TRIB3-silenced cells showed stronger resistance to ER stress-induced apoptosis. These results indicate that TRIB3 is a PERK/ATF4-inducible proapoptotic factor in ER stress.

CaN/FKBP12.6: It was suggested that cytosolic calcium elevation would lead to the opening of mitochondrial permeability transition pore, which resulted in subsequent loss and collapse of mitochondrial membrane potential and thus triggered the intrinsic apoptosis pathway. ${ }^{61} \mathrm{ER}$ is recognized as the cellular 'calcium pool', and under physiological conditions, opening of ER-associated calcium channels are inhibited. For example, FK506-binding protein 12.6 (FKBP12.6) binds to ryanodine receptor2 (RyR2) calcium channel to inhibit calcium outflow from ER under normal physiological conditions. ${ }^{62}$ However, under certain pathological conditions, depletion of ER calcium store was found in cells undergoing ER stress. ${ }^{63}$ In our previous study, we demonstrated that after induction of ER stress, autophosphorylated PERK increased the enzymatic activity of calcineurin $(\mathrm{CaN})$ by direct interaction. $\mathrm{CaN}$ then facilitated the disassociation of FKBP12.6 from RyR2 calcium channel to trigger calcium outflow from the ER to the cytosol. ${ }^{64}$ This Can/FKBP12.6 pathway-regulated calcium overloading could be considered as one of the possible mechanisms of ER stress-induced apoptosis.

\section{Role of PERK in ER Stress-Induced Autophagy}

It is now generally accepted that almost all cells are undergoing process of autophagy at the basal level. Normal cellular function is maintained by the basal autophagy, which selfdigests damaged organelles and proteins by lysomome to provide nascent amino acids and nucleic acids for organelle repair and protein regeneration. Pathological conditions such as oxidative stress and viral infection would initiate autophagy. ${ }^{65}$ The isolation membrane is formed at the preautophagosomal site, which is composed of Atg proteins. Then, the isolation membrane (autophagic membrane) is elongated to form autophagosome with the assistance of ubiqutin-like protein conjugation systems, namely the 
LC3 and Atg12 protein systems, which modify autophgic proteins such as Atg8 and Atg5. An autolysosome where self-digestion occurs is eventually formed by fusion of autophagosome and lysosomal/endosomal vesicles. It was believed that endoplasmic reticulum served as a platform for the initiation of autophagy at the subcellular level. ${ }^{66}$ Furthermore, more and more correlations between three arms of ER stress and autophagy were found in recent studies. ${ }^{67,68}$ Lines of evidences suggested that there were autophagy-dependent cell death under ER stress conditions. ${ }^{69-71}$ Therefore, signaling in ER stress could be the potential switching mechanism between autophagy and apoptosis.

Autophagy is regulated by ER stress pathways. Upon activation of signal transductions in ER stress, the autophagic gene were found as targets of ER stress-related transcriptional factors $^{72-78}$ (Table 2). Mutant huntingtin aggregation-induced cytotoxicity in neurons was one of the critical mechanisms of Huntington's disease. These accumulated mutant huntingtin could be eliminated by autophagic flux but which was found impaired by IRE1/TRAF2 signaling under circumstances of ER stress. ${ }^{79}$ By phosphorylating and dissociating Beclin1 from $\mathrm{Bcl} 2$, death-associated protein kinase 1 (DAPK1) promotes autophagy. $^{80}$ ATF6 was found as an autophagy-positive regulator by interacting with ERK1/2 target site of C/EBP- $\beta$ and form a heterodimer that activates the promoter of DAPK 1. ${ }^{81}$ PERK-governed pathway was also found to have a role in ER stress-induced autophagy.

\section{The involvement of PERK in ER stress-induced autophagy}

elF2a/ATF4 pathway: According to results from several previous studies, during ER stress, elF2a/ATF4 signaling pathway had an important role in inducing and regulating autophagy. ${ }^{75}$ Activation of PERK pathway is crucial for autophagic flux, which maintains cell survival. In yeast and mammals, phosphorylation of elF2 $a$ is required in inducing autophagy. During the autophagic induction phase, several elF2 a phosphorylation-dependent selective translation would lead to Atg12 upregulation, which then stimulates the formation of Atg5-Atg12-Atg16 complex, resulting in the promotion of LC3-I to LC3-II conversion. ${ }^{82}$ Moreover, it was reported that ATF4 activity was essential for some autophagic gene transcription. $^{83}$ In a recent study, by chromatin immunoprecipitation analysis (ChIP) analysis, sets of autophagic genes including Atg3, Atg12, Atg16, Map, Becn1 and Gabarapl2 were identified as targets for ATF4. ${ }^{75}$ Meanwhile, transcriptions of autophagic genes including Sqstm1, Nbr1 and Atg7 were boosted when ATF4 and CHOP were coactivated. ${ }^{75}$

AMPK/mTORC1 pathway: Regulation of autophagy through modulation of the AMP-activated protein kinase (AMPK)/ mammalian target of rapamycin $\mathrm{C} 1$ (mTORC1) pathway by PERK was found in endothelial cells during ECM detachment. ${ }^{84}$ mTOR functions as a protein kinase coordinating multiple cellular metabolic processes. ${ }^{85}$ It is believed that $\mathrm{mTOR}$ is a typical negative autophagic regulator. ${ }^{86}$ mTORC1 is a complex that comprises mTOR, Raptor and mLST8. Inhibition of mTOR is considered to promote
Table 2 Several autophagic genes targeted by ER stress transcription factors

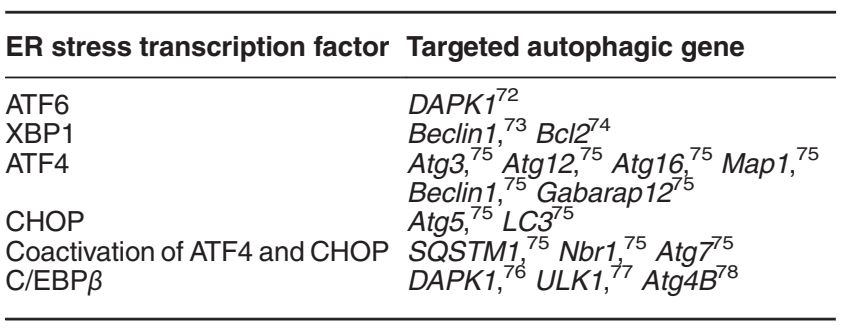

autophagy by regulating Atg1 in yeast and Atg1 complex, ULK (UNC-51-like kinase), in mammals. External stress such as ATP:ADP ratio reversion would lead to the activation of AMPK, which then inhibits the mTOR activity to initiate autophagy. ${ }^{87}$ In endothelial cells, under ER stress induced by ECM detachment, AMPK was found to be activated and induces autophagy by rapidly reproducing ATP to promote cell survival. Importantly, PERK was identified as the upstream activator of AMPK phosphorylation at the AMPK site, which is a substrate for LKB1 ${ }^{84}$ However, more detailed mechanisms concerning this process are still under investigation. The PERK/AMPK/mTORC1 pathway-mediated autophagy was found only in endothelial cells. More studies are needed to clarify whether this is a universal mechanism.

PERK pathway switches signal transduction from autophagy to apoptosis. It may seem contradictory that PERK/ elF2a/ATF4 pathway participated in both ER stress-induced apoptosis and autophagy, but recent studies in selenitetreated leukemia NB4 cells indicated that it was the PERK/ elF2a/ATF4 axis that itself had modulated the switch between autophagy and apoptosis with the assistance of $\mathrm{p} 38 .^{88}$ It was reported in the same study that PERK modulated the phosphorylation of p38, which affected the target selection of ATF4 to mediate the switch between apoptosis and autophagy. P38 was considered the critical factor linking the crosstalk between autophagy and apoptosis by modulating PERK/elF2a/ATF4 signaling. ${ }^{88}$

Under physiological conditions, ER stress-induced intracellular autophagy is maintained at the basal level. In seleniteinduced autophagy in Jurkat cells, by interacting with promoters of autophagic genes, PERK/ elF2a/ATF4 pathway induces autophagy. During this progression, the binding of ATF4 to autophagic gene such as Map1LC3B is directed and promoted by phosphorylated elF4E. ${ }^{89}$ However, under pathological conditions, after ER stress is aroused, this pathway would modulate to shut down autophagy and to initiate apoptosis.

The dual role of p38 as an apoptotic promoter and an autophagic initiator is possible because of the abundance of p38 upstream regulators. It was reported that in human pancreatic cancer cells, PERK activation decreases the expression of Hsp90 and Hsp90-Cdc37 chaperone complex suppressed the autophosphorylation of $\mathrm{p} 38 .{ }^{90}$ Under circumstances of ER stress, in the autophagy-to-apoptosis switching process, activated PERK inhibits the activity of Hsp90-Cdc37 complex to initiate the p38 autophosphorylation. Activated p38 would suppress the phosphorylation of elF4E but increase the phosphorylation of elF2 $a{ }^{88}$ The docking sequence for ATF4, 


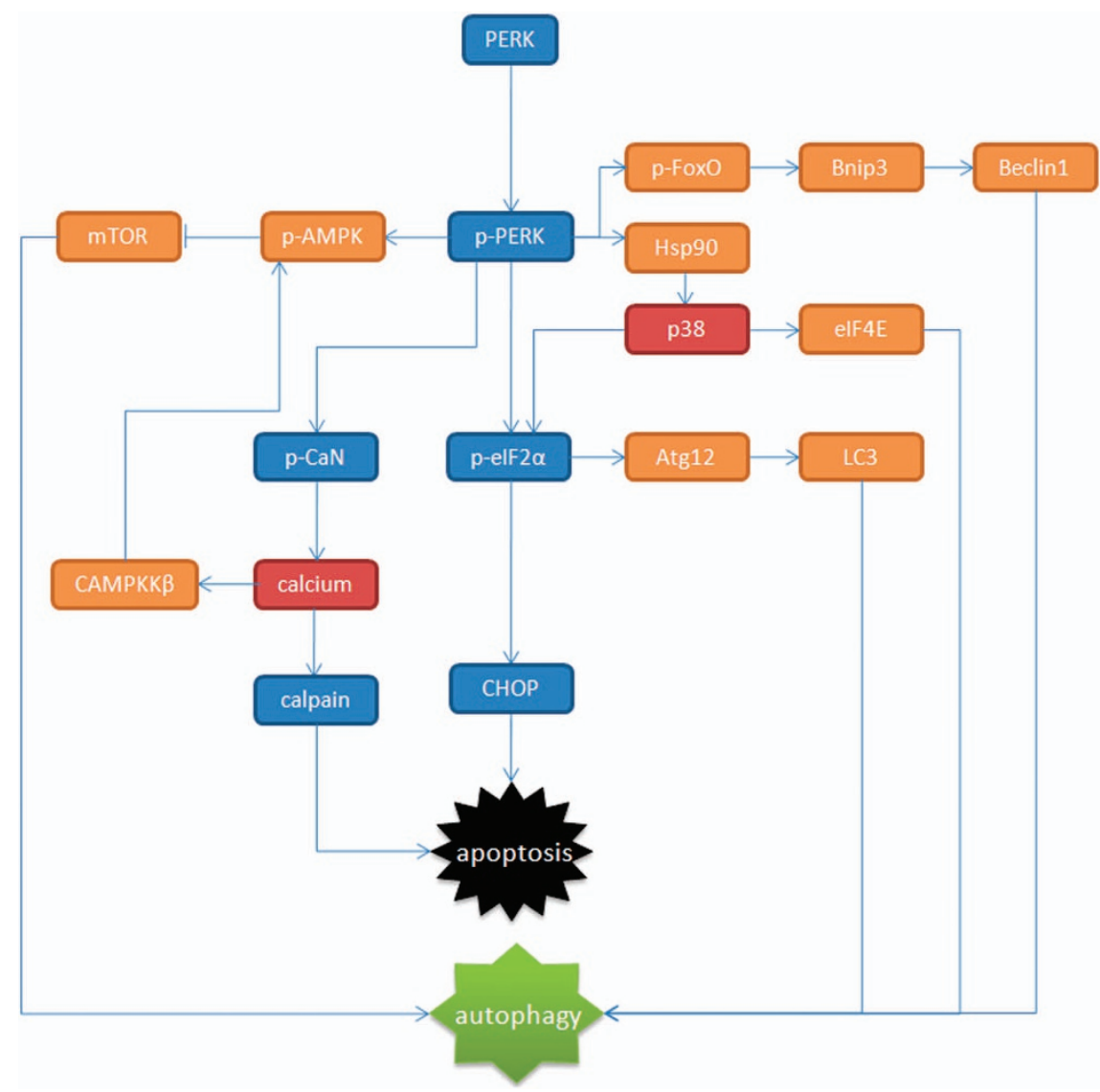

Figure 3 Brief diagram of PERK-dependent pathways in ER stress-induced autophagy and switching mechanism between apoptosis and autophagy. In this figure, pathways marked in blue indicated the pathways resulting in apoptosis; pathways marked in orange indicated pathways leading to autophagy. Molecules marked red (namely p38 and calcium) indicate the key regulator of PERK's switching role between autophagy and apoptosis during ER stress.

CRE-like elements, locates in promoters of both $\mathrm{CHOP}$ and MAP1LC3B. Thus, ATF4 would be more inclined to initiate the binding with $\mathrm{CHOP}$ promoter to induce transcription of proapoptotic genes to trigger programmed cell death. ${ }^{88}$ The switching mechanism is demonstrated briefly in Figure 3.

\section{Perspectives}

As one of the important intracellular organelles, ER participates in executing and regulating multiple cellular fundamental biological functions. Under certain physiological or pathological conditions, as the unfolded/misfolded proteins accumulating in the ER lumen, ER stress is induced. Currently, ER stress is considered as a cell fate-deciding event. If cells are unable to compensate under severe external stimuli, cell apoptosis would be induced by ER stress. If the stimuli are mild, ER stress-induced autophagy would be introduced to promote cell survival by providing nutrients via self-digesting damaged organelles and proteins. This sophisticated but complicated mechanism ascertains the stability of the inner biological environment and strengthens the protective responses to harmful external stimuli.

PERK is an ER-resident protein that mediates signal transduction during ER stress. Along with ATF6 and IRE1, $P E R K$ is also recognized as one of the main transducers of ER stress. The death/survival signals transduced in ER stress are sensed by these transducers to trigger either apoptosis or autophagy. However, according to several previous studies of our team and others, there are some uniqueness of PERK compared with ATF6- or IRE1-governed signaling pathways in inducing apoptosis and autophagy.

In high-glucose-mediated ER stress-induced myocytes apoptosis, we found that although all of the three arms of ER stress were activated, PERK deletion exhibited stronger protective effect against apoptosis compared with ATF6 and IRE1. ${ }^{91}$ On further investigation by subcellular fractionation, PERK was found as a component of mitochondria-associated endoplasmic reticulum membrane (MAM). ${ }^{91,92}$ In other words, PERK is an MAM protein. MAM is described as the physical and functional contact site of ER and mitochondria, which is tightly packed with proteins with various functions including oxidative stress sensing, cell death regulation and so on. ${ }^{93}$ Thus, as an MAM protein, it is possible that PERK carries out more responsibilities in conducting death signals. However, more investigations should be implemented to address PERKspecific role as an MAM protein and its interactions with other MAM proteins.

The PERK/ATF4 signaling is now accepted as a typical pathway mediating ER stress-induced autophagy. It is believed that activated FoxO facilitates the expression of Bnip3, which displaces the autophagic effecter Beclin1 from $\mathrm{Bcl}-\mathrm{XL}$ complexes to induce autophagy. ${ }^{94} \mathrm{~A}$ recent study 
pointed out that PERK could direct phosphorylation of FoxO transcription factor to promote FoxO activity. ${ }^{95}$ It is reasonable for us to speculate that PERK/FoxO could be an alternative PERK- associated pathway mediating ER stress-induced autophagy. Notably, PERK signaling is cell fate deciding in ER stress because of its autophagy-apoptosis switching role. As mentioned in above sections, p38 is tightly associated with the switching function of PERK. Are there other possible mechanisms? After calcium outflow is induced by PERKmediated RyR2 opening, the calmodulin-dependent potein kinase kinase $\beta(\mathrm{CAMPKK} \beta)$ is activated, ${ }^{96}$ which subsequently induces AMPK signaling to affect mTOR-associated autophagy. ${ }^{97}$ Thus, CAMPKK $\beta$ could also be treated as a potential key autophagy-apoptosis switching molecule in PERK signaling. However, these are only reasonable hypothesis, much more studies are still needed.

\section{Conclusion}

According to the literature and our previous studies, although still not completely clear, PERK signaling pathway is potentially highly related with the types of human diseases including Alzheimer's disease, ${ }^{98}$ Parkinson's disease, ${ }^{99}$ Huntington's disease, ${ }^{100}$ encephalomyelitis, ${ }^{101}$ vascular calcification, ${ }^{102}$ arrhythmias, ${ }^{64}$ diabetic cardiomyopathy ${ }^{91}$ and so on. Clarification of basic mechanisms of ER stressinduced apoptosis, autophagy and the crosstalk between them is that these findings would be significant and benefit in interpreting pathological and pathophysiological mechanisms of certain diseases and finding novel therapeutic molecular targets.

\section{Conflict of Interest}

The authors declare no conflict of interest.

1. Boelens J, Lust S, Offner F, Bracke ME, Vanhoecke BW. Review. The endoplasmic reticulum: a target for new anticancer drugs. In Vivo 2007; 21: 215-226.

2. Gregor MF, Hotamisligil GS. Thematic review series: adipocyte biology. Adipocyte stress: the endoplasmic reticulum and metabolic disease. J Lipid Res 2007; 48: 1905-1914.

3. Bollini R, Chrispeels MJ. The rough endoplasmic reticulum is the site of reserve-protein synthesis in developing Phaseolus vulgaris cotyledons. Planta 1979; 146: 487-501.

4. Rizzolo LJ, Kornfeld R. Post-translational protein modification in the endoplasmic reticulum. Demonstration of fatty acylase and deoxymannojirimycin-sensitive alpha-mannosidase activities. J Biol Chem 1988; 263: 9520-9525.

5. Karnik AB, Thakore KN, Nigam SK, Babu KA, Lakkad BC, Bhatt DK et al. Studies on glucose-6-phosphatase, fructose-1,6-diphosphatase activity, glycogen distribution and endoplasmic reticulum changes during hexachlorocyclohexane induced hepatocarcinogenesis in pure inbred Swiss mice. Neoplasma 1981; 28: 575-584.

6. Roitsch T, Lehle L. Post-translational translocation of polypeptides across the mammalian endoplasmic reticulum membrane is size and ribosome dependent. Eur J Biochem 1988; 174: 699-705.

7. Kondratyev M, Avezov E, Shenkman M, Groisman B, Lederkremer GZ. PERK-dependent compartmentalization of ERAD and unfolded protein response machineries during ER stress. Exp Cell Res 2007; 313: 3395-3407.

8. Hampton RY. ER stress response: getting the UPR hand on misfolded proteins. Curr Biol 2000; 10: R518-R521.

9. Kozutsumi Y, Segal M, Normington K, Gething MJ, Sambrook J. The presence of malfolded proteins in the endoplasmic reticulum signals the induction of glucose-regulated proteins. Nature 1988; 332: 462-464.

10. Rao RV, Peel A, Logvinova A, del Rio G, Hermel E, Yokota T et al. Coupling endoplasmic reticulum stress to the cell death program: role of the ER chaperone GRP78. FEBS Lett 2002; 514: 122-128.

11. Lajoie $\mathrm{P}$, Moir RD, Willis IM, Snapp EL. Kar2p availability defines distinct forms of endoplasmic reticulum stress in living cells. Mol Biol Cell 2012; 23: 955-964.

12. Vannuvel K, Renard $P$, Raes M, Arnould T. Functional and morphological impact of ER stress on mitochondria. J Cell Physiol 2013; 228: 1802-1818.
13. Reddy RK, Mao C, Baumeister P, Austin RC, Kaufman RJ, Lee AS. Endoplasmic reticulum chaperone protein GRP78 protects cells from apoptosis induced by topoisomerase inhibitors: role of ATP binding site in suppression of caspase-7 activation. J Biol Chem 2003; 278: 20915-20924.

14. Lee AS. The ER chaperone and signaling regulator GRP78/BiP as a monitor of endoplasmic reticulum stress. Methods 2005; 35: 373-381.

15. Rutkowski DT, Kaufman RJ. A trip to the ER: coping with stress. Trends Cell Biol 2004; 14: 20-28.

16. Ye J, Rawson RB, Komuro R, Chen X, Dave UP, Prywes R et al. ER stress induces cleavage of membrane-bound ATF6 by the same proteases that process SREBPs. Mol Cell 2000; 6: 1355-1364.

17. Hirsch I, Weiwad M, Prell E, Ferrari DM. ERp29 deficiency affects sensitivity to apoptosis via impairment of the ATF6-CHOP pathway of stress response. Apoptosis 2014; 19: $801-815$.

18. Lee K, Tirasophon W, Shen X, Michalak M, Prywes R, Okada T et al. IRE1-mediated unconventional mRNA splicing and S2P-mediated ATF6 cleavage merge to regulate XBP1 in signaling the unfolded protein response. Genes Dev 2002; 16: 452-466.

19. Calfon M, Zeng H, Urano F, Till JH, Hubbard SR, Harding HP et al. IRE1 couples endoplasmic reticulum load to secretory capacity by processing the XBP-1 mRNA. Nature 2002; 415: 92-96.

20. Malhi H, Kaufman RJ. Endoplasmic reticulum stress in liver disease. J Hepatol 2011; 54: 795-809.

21. Sano R, Reed JC. ER stress-induced cell death mechanisms. Biochim Biophys Acta 2013; 1833: 3460-3470.

22. Hollien J, Lin JH, Li H, Stevens N, Walter P, Weissman JS. Regulated Ire1-dependent decay of messenger RNAs in mammalian cells. J Cell Biol 2009; 186: 323-331.

23. Donnelly N, Gorman AM, Gupta S, Samali A. The elF2alpha kinases: their structures and functions. Cell Mol Life Sci 2013; 70: 3493-3511.

24. Marciniak SJ, Garcia-Bonilla L, Hu J, Harding HP, Ron D. Activation-dependent substrate recruitment by the eukaryotic translation initiation factor 2 kinase PERK. J Cell Biol 2006; 172: 201-209.

25. Zhao Y, Guo Z, Lin X, Zhou L, Okoro EU, Fan G et al. Apolipoprotein E-deficient lipoproteins induce foam cell formation by activation of PERK-EIF-2alpha signaling cascade. J Bioanal Biomed 2010; 2: 113-120.

26. Locker N, Easton LE, Lukavsky PJ. HCV and CSFV IRES domain II mediate elF2 release during $80 \mathrm{~S}$ ribosome assembly. EMBO J 2007; 26: 795-805

27. Vattem KM, Wek RC. Reinitiation involving upstream ORFs regulates ATF4 mRNA translation in mammalian cells. Proc Natl Acad Sci USA 2004; 101: 11269-11274.

28. Wek RC, Cavener DR. Translational control and the unfolded protein response. Antioxid Redox Signal 2007; 9: 2357-2371.

29. Saito A, Ochiai K, Kondo S, Tsumagari K, Murakami T, Cavener DR et al. Endoplasmic reticulum stress response mediated by the PERK-eIF2(alpha)-ATF4 pathway is involved in osteoblast differentiation induced by BMP2. J Biol Chem 2011; 286: 4809-4818.

30. Cui W, Li J, Ron D, Sha B. The structure of the PERK kinase domain suggests the mechanism for its activation. Acta Crystallogr D 2011; 67: 423-428.

31. Fang F, Gong PS, Song XF, Gong SL, Wang ZC. Low-dose radiation induces endoplasmic reticulum stress and activates PERK-CHOP signaling pathway in mouse testicular cells]. Zhonghua Nan Ke Xue 2012; 18: 777-782.

32. Yamaguchi H, Wang HG. CHOP is involved in endoplasmic reticulum stress-induced apoptosis by enhancing DR5 expression in human carcinoma cells. J Biol Chem 2004; 279: 45495-45502.

33. Frand AR, Kaiser CA. The ERO1 gene of yeast is required for oxidation of protein dithiols in the endoplasmic reticulum. Mol Cell 1998; 1: 161-170.

34. Szegezdi E, Fitzgerald U, Samali A. Caspase-12 and ER-stress-mediated apoptosis: the story so far. Ann NY Acad Sci 2003; 1010: 186-194.

35. Binet F, Chiasson S, Girard D. Evidence that endoplasmic reticulum (ER) stress and caspase-4 activation occur in human neutrophils. Biochem Biophys Res Commun 2010; 391: $18-23$.

36. Martinez JA, Zhang Z, Svetlov SI, Hayes RL, Wang KK, Larner SF. Calpain and caspase processing of caspase-12 contribute to the ER stress-induced cell death pathway in differentiated PC12 cells. Apoptosis 2010; 15: 1480-1493.

37. Thompson SR, Gulyas KD, Sarnow P. Internal initiation in Saccharomyces cerevisiae mediated by an initiator tRNA/elF2-independent internal ribosome entry site element. Proc Natl Acad Sci USA 2001; 98: 12972-12977.

38. Chambers JE, Dalton LE, Clarke HJ, Malzer E, Dominicus CS, Patel V et al. Actin dynamics tune the integrated stress response by regulating eukaryotic initiation factor 2alpha dephosphorylation. eLife 2015; 4: e04872.

39. Chen $Y$, Gao $H$, Yin $Q$, Chen $L$, Dong $P$, Zhang $X$ et al. ER stress activating ATF4/CHOP-TNF-alpha signaling pathway contributes to alcohol-induced disruption of osteogenic lineage of multipotential mesenchymal stem cell. Cell Physiol Biochem 2013; 32: 743-754.

40. Su N, Kilberg MS. C/EBP homology protein (CHOP) interacts with activating transcription factor 4 (ATF4) and negatively regulates the stress-dependent induction of the asparagine synthetase gene. J Biol Chem 2008; 283: 35106-35117. 
41. Cao J, Dai DL, Yao L, Yu HH, Ning B, Zhang $Q$ et al. Saturated fatty acid induction of endoplasmic reticulum stress and apoptosis in human liver cells via the PERK/ATF4/CHOP signaling pathway. Mol Cell Biochem 2012; 364: 115-129.

42. Qing G, Li B, Vu A, Skuli N, Walton ZE, Liu X et al. ATF4 regulates MYC-mediated neuroblastoma cell death upon glutamine deprivation. Cancer Cell 2012; 22: 631-644.

43. Foster KA, Jane EP, Premkumar DR, Morales A, Pollack IF. Co-administration of ABT-737 and SAHA induces apoptosis, mediated by Noxa upregulation, Bax activation and mitochondrial dysfunction in PTEN-intact malignant human glioma cell lines. $J$ Neurooncol 2014; 120: 459-472.

44. Dong Z, Wang JZ, Yu F, Venkatachalam MA. Apoptosis-resistance of hypoxic cells: multiple factors involved and a role for IAP-2. Am J Pathol 2003; 163: 663-671.

45. de Graaf AO, van Krieken JH, Tonnissen E, Wissink W, van de Locht L, Overes I et al. Expression of C-IAP1, C-IAP2 and SURVIVIN discriminates different types of lymphoid malignancies. Br J Haematol 2005; 130: 852-859.

46. Hamanaka RB, Bobrovnikova-Marjon E, Ji X, Liebhaber SA, Diehl JA. PERKdependent regulation of IAP translation during ER stress. Oncogene 2009; 28 : 910-920.

47. Warnakulasuriyarachchi $\mathrm{D}$, Cerquozzi $\mathrm{S}$, Cheung $\mathrm{HH}$, Holcik M. Translational induction of the inhibitor of apoptosis protein HIAP2 during endoplasmic reticulum stress attenuates cell death and is mediated via an inducible internal ribosome entry site element. J Biol Chem 2004; 279: 17148-17157.

48. Fulda S, Vucic D, Targeting IAP. proteins for therapeutic intervention in cancer. Nat Rev Drug Discov 2012; 11: 109-124.

49. Park ES, Kim J, Ha TU, Choi JS, Soo Hong K, Rho J. TDAG51 deficiency promotes oxidative stress-induced apoptosis through the generation of reactive oxygen species in mouse embryonic fibroblasts. Exp Mol Med 2013; 45: e35.

50. Hossain GS, van Thienen JV, Werstuck GH, Zhou J, Sood SK, Dickhout JG et al. TDAG51 is induced by homocysteine, promotes detachment-mediated programmed cell death, and contributes to the cevelopment of atherosclerosis in hyperhomocysteinemia. J Biol Chem 2003; 278: 30317-30327.

51. Zhou J, Lhotak S, Hilditch BA, Austin RC. Activation of the unfolded protein response occurs at all stages of atherosclerotic lesion development in apolipoprotein E-deficient mice. Circulation 2005; 111: 1814-1821.

52. Baird L, Dinkova-Kostova AT. The cytoprotective role of the Keap1-Nrf2 pathway. Arch Toxicol 2011; 85: 241-272.

53. Cullinan SB, Zhang D, Hannink M, Arvisais E, Kaufman RJ, Diehl JA. Nrf2 is a direct PERK substrate and effector of PERK-dependent cell survival. Mol Cell Biol 2003; 23 : 7198-7209.

54. Del Vecchio CA, Feng Y, Sokol ES, Tillman EJ, Sanduja S, Reinhardt F et al. De-differentiation confers multidrug resistance via noncanonical PERK-Nrf2 signaling. PLOS Biol 2014; 12: e1001945.

55. Digaleh H, Kiaei M, Khodagholi F. Nrf2 and Nrf1 signaling and ER stress crosstalk: implication for proteasomal degradation and autophagy. Cell Mol Life Sci 2013; 70 4681-4694.

56. Zhang B, Wang XQ, Chen HY, Liu BH. Involvement of the Nrf2 pathway in the regulation of pterostilbene-induced apoptosis in HeLa cells via ER stress. J Pharmacol Sci 2014; 126 216-229.

57. Cullinan SB, Diehl JA. Coordination of ER and oxidative stress signaling: the PERK/Nrf2 signaling pathway. Int J Biochem Cell Biol 2006; 38: 317-332.

58. Qian B, Wang H, Men X, Zhang W, Cai H, Xu S et al. TRIB3 [corrected] is implicated in glucotoxicity- and endoplasmic reticulum-stress-induced [corrected] beta-cell apoptosis. $J$ Endocrinol 2008; 199: 407-416.

59. Ishikawa F, Akimoto T, Yamamoto H, Araki Y, Yoshie T, Mori K et al. Gene expression profiling identifies a role for $\mathrm{CHOP}$ during inhibition of the mitochondrial respiratory chain. J Biochem 2009; 146: 123-132.

60. Kim EJ, Lee YJ, Kang S, Lim YB. lonizing radiation activates PERK/elF2alpha/ATF4 signaling via ER stress-independent pathway in human vascular endothelial cells. Int J Radiat Biol 2014; 90: 306-312.

61. Leaver HA, Schou AC, Rizzo MT, Prowse CV. Calcium-sensitive mitochondrial membrane potential in human platelets and intrinsic signals of cell death. Platelets 2006; 17: 368-377.

62. Du Y, Zhao J, Li X, Jin S, Ma WL, Mu Q et al. Dissociation of FK506-binding protein 12.6 kD from ryanodine receptor in bronchial smooth muscle cells in airway hyperresponsiveness in asthma. Am J Respir Cell Mol Biol 2014; 50: 398-408.

63. Hammadi M, Oulidi A, Gackiere F, Katsogiannou M, Slomianny C, Roudbaraki M et al. Modulation of ER stress and apoptosis by endoplasmic reticulum calcium leak via translocon during unfolded protein response: involvement of GRP78. FASEB J 2013; 27: 1600-1609.

64. Liu Z, Cai H, Zhu H, Toque H, Zhao N, Qiu C et al. Protein kinase RNA-like endoplasmic reticulum kinase (PERK)/calcineurin signaling is a novel pathway regulating intracellula calcium accumulation which might be involved in ventricular arrhythmias in diabetic cardiomyopathy. Cell Signal 2014; 26: 2591-2600.

65. Ouyang L, Shi Z, Zhao S, Wang FT, Zhou TT, Liu B et al. Programmed cell death pathways in cancer: a review of apoptosis, autophagy and programmed necrosis. Cell Prolif2012; 45 487-498.

66. Mijaljica D, Prescott M, Devenish RJ. Endoplasmic reticulum and Golgi complex: contributions to, and turnover by, autophagy. Traffic 2006; 7: 1590-1595.
67. Yorimitsu T, Nair U, Yang Z, Klionsky DJ. Endoplasmic reticulum stress triggers autophagy. J Biol Chem 2006; 281: 30299-30304

68. Yorimitsu T, Klionsky DJ. Endoplasmic reticulum stress: a new pathway to induce autophagy. Autophagy 2007; 3: 160-162.

69. Salazar M, Carracedo A, Salanueva IJ, Hernandez-Tiedra S, Lorente M, Egia A et al. Cannabinoid action induces autophagy-mediated cell death through stimulation of ER stress in human glioma cells. J Clin Invest 2009; 119: 1359-1372.

70. Gozuacik D, Bialik S, Raveh T, Mitou G, Shohat G, Sabanay H et al. DAP-kinase is a mediator of endoplasmic reticulum stress-induced caspase activation and autophagic cell death. Cell Death Differ 2008; 15: 1875-1886.

71. Rubiolo JA, Lopez-Alonso H, Martinez P, Millan A, Cagide E, Vieytes MR et al. Yessotoxin induces ER-stress followed by autophagic cell death in glioma cells mediated by mTOR and BNIP3. Cell Signal 2014; 26: 419-432.

72. Gade P, Manjegowda SB, Nallar SC, Maachani UB, Cross AS, Kalvakolanu DV. Regulation of the death-associated protein kinase 1 expression and autophagy via ATF6 requires apoptosis signal-regulating kinase 1. Mol Cell Biol 2014; 34: 4033-4048.

73. Margariti A, Li H, Chen T, Martin D, Vizcay-Barrena G, Alam S et al. XBP1 mRNA splicing triggers an autophagic response in endothelial cells through BECLIN-1 transcriptional activation. J Biol Chem 2013; 288: 859-872.

74. Gomez BP, Riggins RB, Shajahan AN, Klimach U, Wang A, Crawford AC et al. Human $\mathrm{X}$-box binding protein-1 confers both estrogen independence and antiestrogen resistance in breast cancer cell lines. FASEB J 2007; 21: 4013-4027.

75. B'Chir W, Maurin AC, Carraro V, Averous J, Jousse C, Muranishi Y et al. The elF2alpha/ ATF4 pathway is essential for stress-induced autophagy gene expression. Nucleic Acids Res 2013; 41: 7683-7699.

76. Gade P, Roy SK, Li H, Nallar SC, Kalvakolanu DV. Critical role for transcription factor $\mathrm{C} / \mathrm{EBP}$-beta in regulating the expression of death-associated protein kinase 1. $\mathrm{Mol} \mathrm{Cell} \mathrm{Biol}$ 2008; 28: 2528-2548.

77. Ma D, Panda S, Lin JD. Temporal orchestration of circadian autophagy rhythm by C/EBPbeta. EMBO J 2011; 30: 4642-4651.

78. Guo L, Huang JX, Liu Y, Li X, Zhou SR, Qian SW et al. Transactivation of Atg4b by C/EBPbeta promotes autophagy to facilitate adipogenesis. Mol Cell Biol 2013; 33: 3180-3190.

79. Lee H, Noh JY, Oh Y, Kim Y, Chang JW, Chung CW et al. IRE1 plays an essential role in ER stress-mediated aggregation of mutant huntingtin via the inhibition of autophagy flux. Hum Mol Genet 2012; 21: 101-114.

80. Choi MS, Kim Y, Jung JY, Yang SH, Lee TR, Shin DW. Resveratrol induces autophagy through death-associated protein kinase 1 (DAPK1) in human dermal fibroblasts under normal culture conditions. Exp Dermatol 2013; 22: 491-494.

81. Gade P, Ramachandran G, Maachani UB, Rizzo MA, Okada T, Prywes R et al. An IFN-gamma-stimulated ATF6-C/EBP-beta-signaling pathway critical for the expression of death associated protein kinase 1 and induction of autophagy. Proc Natl Acad Sci USA 2012; 109: 10316-10321.

82. Kouroku Y, Fujita E, Tanida I, Ueno T, Isoai A, Kumagai H et al. ER stress (PERK/elF2alpha phosphorylation) mediates the polyglutamine-induced LC3 conversion, an essential step for autophagy formation. Cell Death Differ 2007; 14: 230-239.

83. Rzymski T, Milani M, Pike L, Buffa F, Mellor HR, Winchester $L$ et al. Regulation of autophagy by ATF4 in response to severe hypoxia. Oncogene 2010; 29: 4424-4435.

84. Avivar-Valderas A, Bobrovnikova-Marjon E, Alan Diehl J, Bardeesy N, Debnath J, Aguirre-Ghiso JA. Regulation of autophagy during ECM detachment is linked to a selective inhibition of mTORC1 by PERK. Oncogene 2013; 32: 4932-4940.

85. Zarogoulidis $\mathrm{P}$, Lampaki $\mathrm{S}$, Turner JF, Huang $\mathrm{H}$, Kakolyris $\mathrm{S}$, Syrigos $\mathrm{K}$ et al. mTOR pathway: a current, up-to-date mini-review (Review). Oncol Lett 2014; 8: 2367-2370.

86. Dunlop EA, Tee AR. mTOR and autophagy: a dynamic relationship governed by nutrients and energy. Semin Cell Dev Biol 2014; 36: 121-129.

87. Shi WY, Xiao D, Wang L, Dong LH, Yan ZX, Shen ZX et al. Therapeutic metformin/AMPK activation blocked lymphoma cell growth via inhibition of mTOR pathway and induction of autophagy. Cell Death Dis 2012; 3: e275.

88. Jiang Q, Li F, Shi K, Wu P, An J, Yang Y et al. Involvement of p38 in signal switching from autophagy to apoptosis via the PERK/elF2alpha/ATF4 axis in selenite-treated NB4 cells. Cell Death Dis 2014; 5: e1270.

89. Jiang $Q$, Li F, Shi K, Wu P, An J, Yang Y et al. ATF4 activation by the p38MAPK-elF4E axis mediates apoptosis and autophagy induced by selenite in Jurkat cells. FEBS Lett 2013; 587: 2420-2429.

90. Adachi S, Yasuda I, Nakashima M, Yamauchi T, Yamauchi J, Natsume H et al. HSP90 inhibitors induce desensitization of EGF receptor via p38 MAPK-mediated phosphorylation at Ser1046/1047 in human pancreatic cancer cells. Oncol Rep 2010; 23: 1709-1714.

91. Liu ZW, Zhu HT, Chen KL, Dong X, Wei J, Qiu C et al. Protein kinase RNA-like endoplasmic reticulum kinase (PERK) signaling pathway plays a major role in reactive oxygen species (ROS)-mediated endoplasmic reticulum stress-induced apoptosis in diabetic cardiomyopathy. Cardiovasc Diabetol 2013; 12: 158

92. Verfaillie T, Rubio N, Garg AD, Bultynck G, Rizzuto R, Decuypere JP et al. PERK is required at the ER-mitochondrial contact sites to convey apoptosis after ROS-based ER stress. Cell Death Differ 2012; 19: 1880-1891. 
93. Pinton P, Giorgi C, Missiroli S, Patergnani S, Duszynski J, Wieckowski M. Mitochondria-associated membranes (MAMs): composition, molecular mechanisms and physiopathological implications. Antioxid Redox Signal 2015; 22: 995-1019.

94. Lin A, Yao J, Zhuang L, Wang D, Han J, Lam EW et al. The FoxO-BNIP3 axis exerts a unique regulation of mTORC1 and cell survival under energy stress. Oncogene 2014; 33: 3183-3194.

95. Zhang W, Hietakangas V, Wee S, Lim SC, Gunaratne J, Cohen SM. ER stress potentiates insulin resistance through PERK-mediated FOXO phosphorylation. Genes Dev 2013; 27: $441-449$.

96. Wen L, Chen Z, Zhang F, Cui X, Sun W, Geary GG et al. $\mathrm{Ca}^{2+} /$ calmodulin-dependent protein kinase kinase beta phosphorylation of Sirtuin 1 in endothelium is atheroprotective. Proc Natl Acad Sci USA 2013; 110: E2420-7.

97. Yang S, Wang J. Estrogen activates AMP-activated protein kinase in human endothelial cells via ERbeta/Ca/calmodulin-dependent protein kinase kinase beta pathway. Cell Biochem Biophys 2015; 24: 24.

98. Ma T, Trinh MA, Wexler AJ, Bourbon C, Gatti E, Pierre P et al. Suppression of elF2alpha kinases alleviates Alzheimer's disease-related plasticity and memory deficits. Nat Neurosci 2013; 16: 1299-1305.

99. Hashida K, Kitao Y, Sudo H, Awa Y, Maeda S, Mori K et al. ATF6alpha promotes astroglial activation and neuronal survival in a chronic mouse model of Parkinson's disease. PLOS One 2012; 7: e47950.
100. Vidal RL, Hetz C. Crosstalk between the UPR and autophagy pathway contributes to handling cellular stress in neurodegenerative disease. Autophagy 2012; 8: 970-972.

101. Meares GP, Liu Y, Rajbhandari R, Qin H, Nozell SE, Mobley JA et al. PERK-dependent activation of JAK1 and STAT3 contributes to endoplasmic reticulum stress-induced inflammation. Mol Cell Biol 2014; 34: 3911-3925.

102. Masuda M, Miyazaki-Anzai S, Levi M, Ting TC, Miyazaki M. PERK-elF2alpha-ATF4-CHOP signaling contributes to TNFalpha-induced vascular calcification. J Am Heart Assoc 2013; 2: 0000238.

(c) (i) Cell Death and Disease is an open-access journal published by Nature Publishing Group. This work is licensed under a Creative Commons Attribution 4.0 International License. The images or other third party material in this article are included in the article's Creative Commons license, unless indicated otherwise in the credit line; if the material is not included under the Creative Commons license, users will need to obtain permission from the license holder to reproduce the material. To view a copy of this license, visit http://creativecommons.org/licenses/by/4.0/ 